\title{
An Analysis of Factors Impacting Design Self-Efficacy of Senior Design Stu- dents
}

\section{Dr. Joanna Tsenn, Texas A\&M University}

Joanna Tsenn is an Assistant Professor of Instruction in the J. Mike Walker '66 Department of Mechanical Engineering at Texas A\&M University. She earned her B.S. from the University of Texas at Austin and her Ph.D. from Texas A\&M University. She coordinates the mechanical engineering senior capstone design projects and teaches senior design lectures and studios. Her research interests include engineering education and engineering design methodology.

\section{Mrs. Heather S. Lewis, Texas A\&M University \\ Dr. Astrid Layton, Texas A\&M University}

Astrid Layton is an assistant professor at Texas A\&M University in the Mechanical Engineering department and received her Ph.D. from Georgia Institute of Technology in Atlanta, Georgia. She is interested in bio-inspired system design problems and is currently working at the intersection of ecology and engineering for the design of complex human networks and systems. 


\section{An Analysis of Factors Impacting Design Self-Efficacy of Senior Design Students}

In many engineering senior design programs, students are taught an engineering design process that they apply to a real-world, engineering design problem. This study examined how different factors from that experience impact a student's design self-efficacy, or their belief in their own ability to complete engineering design tasks. Self-efficacy has been shown to influence a person's actions, where those with higher self-efficacy will challenge themselves with higher goals and increased persistence and perseverance after experiencing setbacks. The increased effort, perseverance, and persistence results in an increased likelihood that the person will successfully achieve their goal.

The mechanical engineering students surveyed here complete a two-semester senior design program, working in teams to complete an open-ended design project. Each project is different, resulting in a different senior design experience; however, the goal of the program is to graduate mechanical engineers with high design self-efficacy. This study collected 491 student exit survey responses over the course of five semesters to investigate the impact of student project experience on four design self-efficacy self-concepts (confidence, motivation, success, and anxiety). Seven factors were used to determine differences between student experiences: gender, project sponsor type, project validation method used, average weekly effort expended outside of class, project satisfaction, project sponsor satisfaction, and sponsor guidance provided. The analysis found that student effort and overall project satisfaction were related to the design selfefficacy self-concept scores, although gender, validation method, and amount of sponsor guidance were not. The results suggest that the type of project given to the students has less impact on self-efficacy than how the students choose to work with it. The study's outcomes will be used to direct future senior design program management and guide further research towards improving student outcomes.

\section{Introduction}

The Texas A\&M University mechanical engineering senior capstone program is a two-semester sequence which teaches the engineering design process and applies associated tools to solve realworld problems. Students are divided into small teams and each team is given a scope of work from a project sponsor. Project sponsorship comes from industry, academia, national laboratories and service entities. Through weekly lectures and studio meetings, instructors work with teams to apply the design tools to their problem and scope of work. While each project is unique, student teams generally follow a similar process, developing concepts and fully designing the final concept in the first semester, and developing and executing a validation plan in the second semester. The goal of the program is to provide a significant design experience for students through which they can apply the various theoretical knowledge and analytical skills that they have collected in their previous coursework. Since practicing engineers will employ the design process repeatedly, the program also seeks to help students develop a high level of design selfefficacy, the belief in one's ability to complete engineering design tasks. Engineers problemsolve by practicing design tasks. As a result, design self-efficacy is a critical component of a successful engineer [1]. Preparing students to become successful engineers, in both industry and 
academia, therefore demands that design tasks be taught to a level where students may obtain self-efficacy [2, 3]. The importance of design tasks has also been acknowledged by the Accreditation Board for Engineering and Technology (ABET). This work seeks to measure the impact of different variables on design self-efficacy, based on the specific project experiences of the students at the end of their two-semester capstone design experience. The student experience is measured using gender, project type, student reported satisfaction with both their project and project sponsor (referred to as their customer), guidance from the sponsor, and the students' perceived effort over the two semesters. Understanding factors that positively influence student design self-efficacy can then inform future program components and decisions.

\section{Background}

\section{An Introduction to Self-Efficacy}

Self-efficacy originates from social cognitive theory and the study of people's beliefs in their own capabilities and how that is tied to their motivation $[4,5]$. This makes self-efficacy an interesting tool for evaluating the success of an educational program. Rather than focusing on course content, this approach focuses on what the student believes s/he can successfully put into practice. Research has shown that self-efficacy belief in students is a strong determinant of their performance and that teachers should pay more attention to students' perception of competence than their actual competence [5]. Cognitive science states that a person's belief in their own capabilities can increase through four means: 1) mastery experiences; 2) vicarious experiences; 3) verbal or social persuasions; and 4) physiological states [6]. The two-semester long mechanical engineering senior design program provides students the opportunity to encounter all four experiences.

\section{Engineering Design Self-Efficacy Instruments}

Educators and researchers worldwide use self-efficacy to measure student confidence in using taught material. Predictive self-efficacy assessments can be difficult to create [7]. In 2010, Carberry et al. created a 36 question online test, the results of which support the importance of self-efficacy in assessing student learning in engineering [1]. This 36-question test is now referred to as the Carberry Design Self-Efficacy Instrument and is commonly used in formatting design self-efficacy questionnaires. The researchers collected 202 responses from individuals with diverse engineering experiences and found that they could measure respondents' design self-efficacy to a significant degree through questions on motivation, anxiety, outcome expectancy, and experience level. Brennan and Hugo also developed a self-efficacy survey focusing specifically on engineering graduates during a six-year study [8]. The 38-question survey addressed 'the 12 engineering graduate attributes' as defined by the Canadian Engineering Accreditation Board (CEAB), one of which was “design.” The 271 respondents were mechanical engineering students taking a two-semester senior design course in their final year of study. The results suggested that the survey was an effective and reliable tool for collecting self-efficacy assessments. Seth et al. collected a minimum of 55 responses from undergraduate junior and senior engineering students three times during a 10-week design course on their design self-efficacy [9]. The survey covered nine design-related tasks, chosen as a 
combination of ABET criteria [10] with other engineering self-efficacy tasks, and were selected to measure design self-efficacy related to problem solving skills. Gains in design self-efficacy and problem-solving skills were reported in all 20 activities over the 10 weeks of the course.

\section{Engineering Design Self-Efficacy and Gender}

Many studies have shown that low self-efficacy in engineering, often in terms of feelings of inclusion, is a factor contributing to the profession's difficulties with the retention of women [1114]. In an effort to improve retention of women in the undergraduate mechanical engineering program, male/female information was collected to better understand how gender may relate to the design self-efficacy of students at the completion of their capstone projects. Currently women make up approximately $18.6 \%$ of the undergraduate mechanical engineering program and 16\% of the surveyed students in this study. A study by Mamaril in 2014 concluded that design selfefficacy did not differ by gender or year level [15]. Self-efficacy literature about undergraduate women engineering students is often contradictory, supporting the need to continue to collect gender information in engineering self-efficacy studies [11]. Additionally, no studies have investigated the effect of gender on design self-efficacy and so the results here contribute to fill this gap.

\section{Nonstandard Teaching Environments}

The student teams in the mechanical engineering senior capstone design course series each have unique projects, sponsors, different team compositions, making it difficult to ensure that each student walks away with a sense of design self-efficacy. Self-efficacy theory states that the level of self-efficacy for any task will be influenced by concepts such as motivation, outcome expectation, and anxiety or self-doubt regarding the task [16]. Measuring design self-efficacy as a result of the senior design program, despite different projects, is therefore broken down into measuring individual student confidence, motivation, expectations of success, and anxiety associated with completing generic design tasks in the future. The mechanical engineering senior design capstone program teaches a structured design process. The students apply this process to highly variable projects, giving them a unique opportunity to actively learn both the fundamentals of the design process as well as how to adapt the process in different situations. This teaching method has been shown to foster problem-solving skills that are crucial for their success post-graduation $[9,17,18]$. Self-efficacy in a complex and free form learning environment is less understood [19]. Unstructured learning environments are becoming more prevalent with the rise of 'active learning' educational initiatives. These active learning projectbased environments have significant quantitative support for improving students' overall learning and retention [20]; however, the design of these classes can be difficult, especially in engineering. As such, the results of this study have the potential to aid in the design of popular unstructured learning environments.

As they approach the completion of their undergraduate engineering degree, it is expected that students are at a stage of "conscious competence" where they are "increasingly aware of what they do not know, and consequently, of what they need to learn” [21]. This state has been hypothesized to affect engineering self-efficacy both negatively and positively: confidence in 
what you do and do not know can both increase and decrease a person's comfort in successfully completing a task. Few studies have been conducted to specifically measure the design selfefficacy of engineering students (e.g. [9, 22]), and none have been found to focus exclusively on the design-self efficacy of students at the end of their studies. The large volume and the experience-level of the students surveyed, as well as the design-focus of the survey, make the results presented here important to the improvement of engineering education for developing successful engineers.

\section{Methods}

\section{Mechanical Engineering Senior Capstone Design Program}

The objective of the capstone design program is to teach senior engineering students a top-down design process through a challenging, real-world design project that encourages innovation. The program consists of a series of two courses that all students are required to complete prior to graduation. The first course, MEEN 401 Introduction to Mechanical Engineering Design, focuses on learning about problem clarification, customer needs analysis, identifying requirements, generating concepts, concept selection, and project management. The students are expected to apply these topics to their specific design problem. The first semester is organized to conclude with student teams' down-selecting to final concepts and a detailed plan for their second semester's work. The second semester, MEEN 402 Intermediate Design, includes lecture topics such as failure modes and risk analysis, modeling, manufacturing, product liability, and ethical responsibility. The student design teams spend the semester validating their selected solution in the form of simulation, analysis, prototyping, and/or testing. The second semester of the capstone design program is significantly more freeform resulting in a different experience for each team and individual.

Students attend both a regular lecture and studio component throughout each semester. Lecture occurs twice a week in 50-minute sessions with a class of about 30-100 students. The student teams apply lecture material to their specific design projects in the studio component. The studios are smaller, typically consisting of 20-25 students working in teams of 4-7 students. Each studio section is scheduled to meet for three hours once a week with a dedicated studio instructor who serves as a mentor for the section.

During the final weeks of MEEN 402 (the second semester of senior design), the senior design students are voluntarily surveyed to gather their feedback on self-efficacy and their thoughts on the program. The goal of the survey is to obtain constructive feedback to improve the capstone program, both in terms of project scope and sponsor interactions. At the time of the survey, the student teams are finishing their projects and most students are completing their final undergraduate semester.

\section{Design Self-Efficacy and Student Experience Factors Survey}

A previous self-efficacy study was conducted relating to student grade level (defined by degree plan progression) of mechanical engineering students at the same institution [7]. That survey looked at the relationship between overall design self-efficacy in freshman, sophomore, and 
senior level students and the results they produced when given a common design problem. The study presented here differs significantly in that it investigates the impact of different variables on design self-efficacy based on the project experience of each student. Project experience is defined here by gender, project sponsor type, project validation method used, satisfaction with project and sponsor, level of guidance originating from the sponsor, and perceived effort level.

The Carberry Design Self-Efficacy Instrument [1] was used as the basis for this study's student questionnaire because of its focus on design self-efficacy. This instrument is a proven method for learning about the students' perceptions of their engineering design abilities [1, 7]. In Carberry's survey, design self-efficacy is broken down into confidence in ability, motivation for performance, perceived success, and task anxiety. Each design self-efficacy self-concept was phrased as a question with regards to nine different design related tasks (engineering design as a whole and the eight steps of the engineering design process). The students were asked to report on a scale of 0-100 in 10-point increments how they felt about each task. Table 1 shows an example of one question students were asked to answer.

The four design self-efficacy self-concepts used were:

- Confidence: your belief in your current ability to perform the design tasks

- Motivation: how motivated you would be to perform the design tasks

- Success: belief you would be successful in performing the design tasks

- Anxiety: how apprehensive you would be in performing the design tasks

The nine design related tasks used were:

- Conduct engineering design

- Identify a design need

- Research a design need

- Develop design solutions

- Select the best possible design

- Construct a prototype

- Evaluate and test a design

- Communicate a design

- Redesign

The survey also included questions about the student experience with the goal of identifying the types of projects and sponsor technical customer relationships that would be most beneficial for future students. If certain types of projects and relationships are correlated to higher selfefficacy, the senior design coordinator can select those types of projects in the future as well as advise technical customers to interact with the students in a particular manner. To learn about types of projects that impact self-efficacy, students were asked about their sponsor type and the method used to validate their design. To learn about the students' interaction and relationship with their sponsor technical customer, students were surveyed regarding guidance level provided by their contact and their satisfaction with the point of contact. Finally, to gauge the overall project experience, students were queried regarding their expended effort on the project and their 
project satisfaction. The surveys were distributed during the course, but completion and resubmission of the survey was voluntary. The surveys were administered to the students in the final three weeks of their second semester of senior design, corresponding to the end of their time in the mechanical engineering program.

Table 1. An example of one of the questions in the design self-efficacy survey: "Rate your degree of CONFIDENCE (i.e. belief in your current ability) to perform the following tasks by recording a number from 0 to 100 . ( $0=$ cannot do at all; $50=$ moderately can do; $100=$ highly certain can do).”

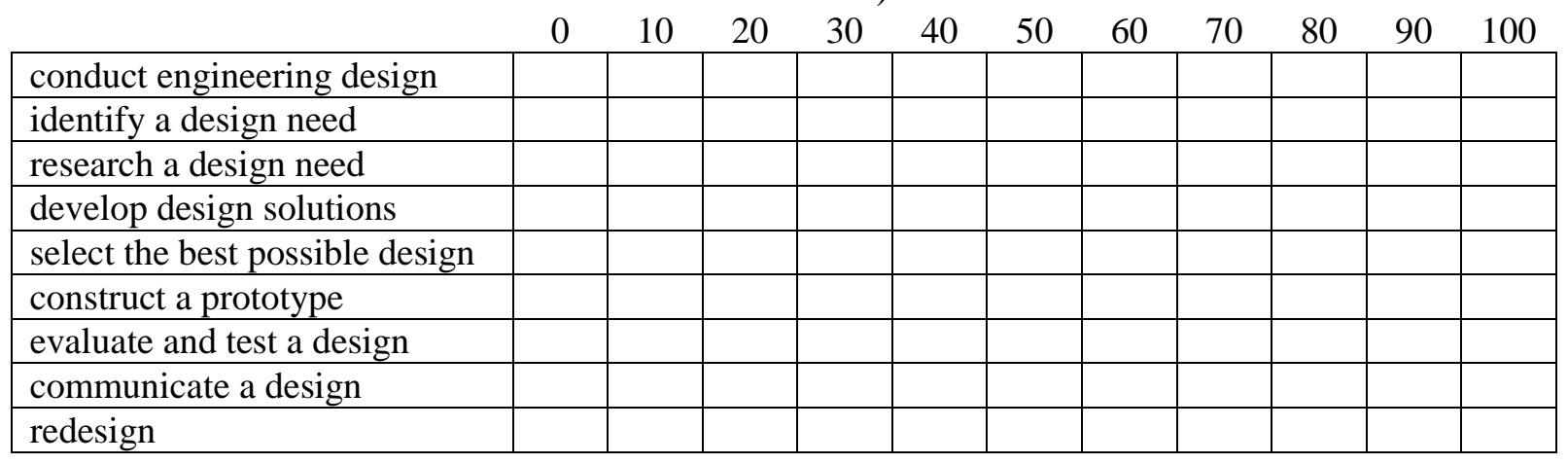

Student experience factors used in this study include:

1. Gender: male, female, other/prefer not to respond

2. Project sponsor type: from where the project originated. The options were industry, faculty, national laboratory, or service.

3. Project validation method: students used various validation methods, some of which they were familiar and some of which were new to them. The options were physical product and testing, simulation and analysis (FEA, CFD, etc.), calculations, other.

4. Effort level: the average hours per week a student spent on project-related work outside of lecture and studio. The options were less than 4 hours, 4-8 hours, 8-12 hours, and more than 12 hours.

5. Project satisfaction: The options were strongly unsatisfied, unsatisfied, neutral, satisfied, and strongly satisfied.

6. Project sponsor or "technical customer" satisfaction: The options were strongly unsatisfied, unsatisfied, neutral, satisfied, and strongly satisfied.

7. Guidance level from sponsor: how directed their work was by the sponsor, or the amount of freedom the students had in all aspects of the design. The options were measured on a scale of 1-5 where 1 was no guidance, 3 was collaborative, and 5 was told exactly what to do.

\section{Data Analysis}

For each student, the nine design-related tasks on the Carberry survey were averaged to represent their score for the self-concepts of confidence, motivation, success, and anxiety. Then, each of the seven experience factors were compared to the four self-concepts. To determine if a statistically significant difference between gender and the self-concepts existed, independent samples t-tests were performed. For the remaining six factors, one-way between subject 
ANOVAs were run with each factor as an independent variable and the self-concept scores as dependent variables. If the ANOVA indicated that a statistical significance existed, Tukey's honestly significant difference (HSD) post hoc test was conducted to determine which specific groups had significant differences.

\section{Results and Discussion}

Usable responses totaled 491 and were collected from graduating senior students (incomplete responses were not used in the analysis). All data was self-reported by the students and voluntarily provided. Among the respondents, 78 were female, 390 were male, and 23 reported other or did not respond. Responses were collected over five semesters: Spring 2017, Summer 2017, Fall 2017, Spring 2018, and Fall 2018.

\section{Design Self-Efficacy to Gender}

The mean values for the student responses regarding their self-efficacy and their reported gender are detailed in Table 2. In this study, undergraduate mechanical engineering women were found to have no significant difference from men in their self-perceived design self-efficacy. These female students are at the end of their degree program and about to successfully graduate with a degree in mechanical engineering. Future work will include a version of the survey administered to students joining the mechanical engineering department and again at the start of the capstone design program to capture the effect of the capstone experience on design self-efficacy. The results will be compared to existing research documenting that female students experience a loss in self-efficacy as they move through an undergraduate engineering program [13]. Design teams had anywhere from 0-5 women on the team, however most teams include only one or two. Future work can additionally follow differences in self-efficacy when a student is the only woman on a design team versus on a team that included one or more of her female peers.

Table 2. Self-concept means and standard deviations by gender with independent samples t-test results.

\begin{tabular}{|c|c|c|c|c|c|c|}
\cline { 2 - 7 } \multicolumn{1}{c|}{} & \multicolumn{2}{c|}{ Female } & \multicolumn{2}{c|}{ Male } & \multicolumn{2}{c|}{ t-test } \\
\cline { 2 - 7 } \multicolumn{1}{c|}{} & M & SD & M & SD & t-value & p-value \\
\hline Confidence & 82.217 & 9.575 & 82.336 & 10.476 & 0.101 & 0.920 \\
\hline Motivation & 79.628 & 13.858 & 77.479 & 15.806 & -1.234 & 0.219 \\
\hline Success & 79.170 & 11.847 & 80.497 & 11.847 & 0.909 & 0.365 \\
\hline Anxiety & 39.026 & 22.652 & 34.845 & 23.751 & -1.438 & 0.141 \\
\hline
\end{tabular}

\section{Design Self-Efficacy to Project Sponsor Type}

The mean values for the student responses regarding their self-efficacy and their project type can be seen in Figure 1. In a small number of instances, students reported having a project that spanned more than one project type. The students' responses were therefore counted in both categories. Additionally, four students reported their project as "other" and their responses were omitted from the analysis. One-way between subjects ANOVAs were conducted to compare the effect of project sponsorship type on each of the four design self-efficacy self-concepts for 
faculty, industry, national laboratory, and service projects. The only design self-efficacy selfconcept that had a statistically significant difference for the project type was the expectation of success (Table 3). A Tukey's HSD test showed that students on faculty projects have significantly higher expectations of success than those on industry projects $(p=0.048)$. A myriad of factors may influence this outcome, and additional work is needed to determine how students' expectation of future success is influenced by project sponsor type. Differences between all the other project types were not statistically significant.

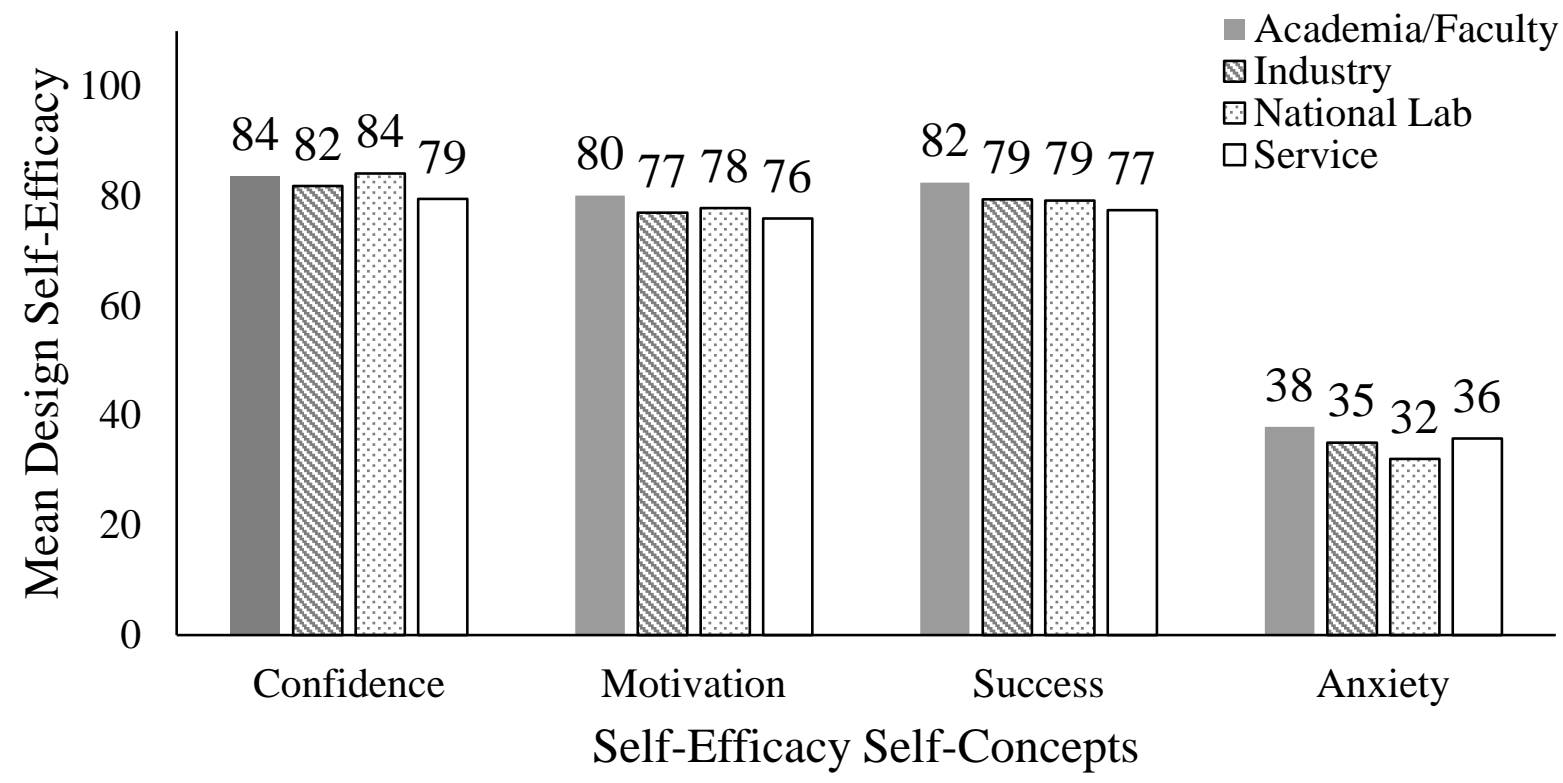

Figure 1. The mean engineering design self-efficacy, represented by the four design self-efficacy self-concepts, for each of the four project types. Project types were academia/faculty (gray), industry (diagonals), national lab (dotted), or service (white).

Table 3. One-way between subject ANOVA results for project sponsor types.

\begin{tabular}{|c|c|c|c|c|c|}
\cline { 2 - 6 } \multicolumn{1}{c|}{} & SS & df & MS & F-value & p-value \\
\hline Confidence & 544.674 & 3 & 181.558 & 1.678 & 0.171 \\
\hline Motivation & 1051.995 & 3 & 350.665 & 2.683 & $\mathbf{0 . 0 4 6}$ \\
\hline Success & 1110.216 & 3 & 370.072 & 1.487 & 0.217 \\
\hline Anxiety & 1091.460 & 3 & 363.820 & 0.647 & 0.584 \\
\hline
\end{tabular}

\section{Design Self-Efficacy to Validation Method Used}

The mean values for the student responses regarding their self-efficacy and project validation method can be seen in Figure 2. In some instances, students reported validating their project using multiple methods. The students' responses were therefore counted in multiple categories. No statistically significant difference was found for any of the self-efficacy self-concepts related to the type of validation method chosen by the student teams (Table 4). 
The results of the project validation method employed were surprising to the course instructors and organizers. Physical product testing and simulation and analysis methods are typically new experiences for students. As a result, it was expected that those students who had gained new knowledge would report a significantly higher self-efficacy. However, the analysis of the survey results suggests that even if students are not necessarily learning a new skill, such as they would be through prototyping and using new software, the application of equations and calculations to real-world problems provided a similar result in terms of the students' feelings of design selfefficacy. The "other" response did show slightly lower motivation, a slightly higher expectation of success, and a higher level of anxiety. The authors' suspect that teams validating using an "other" method are learning something even further outside of their comfort zone for mechanical engineering. Thus, they may have a low motivation and could be anxious about the results, but after going through the experience they have a higher expectation of success. A large standard error exists with "other" so this hypothesis cannot be said to be consistent for all respondents. Future work will seek to further define the different validation methods used and any possible prior experience the student may have had with the method in order to gain additional clarity.

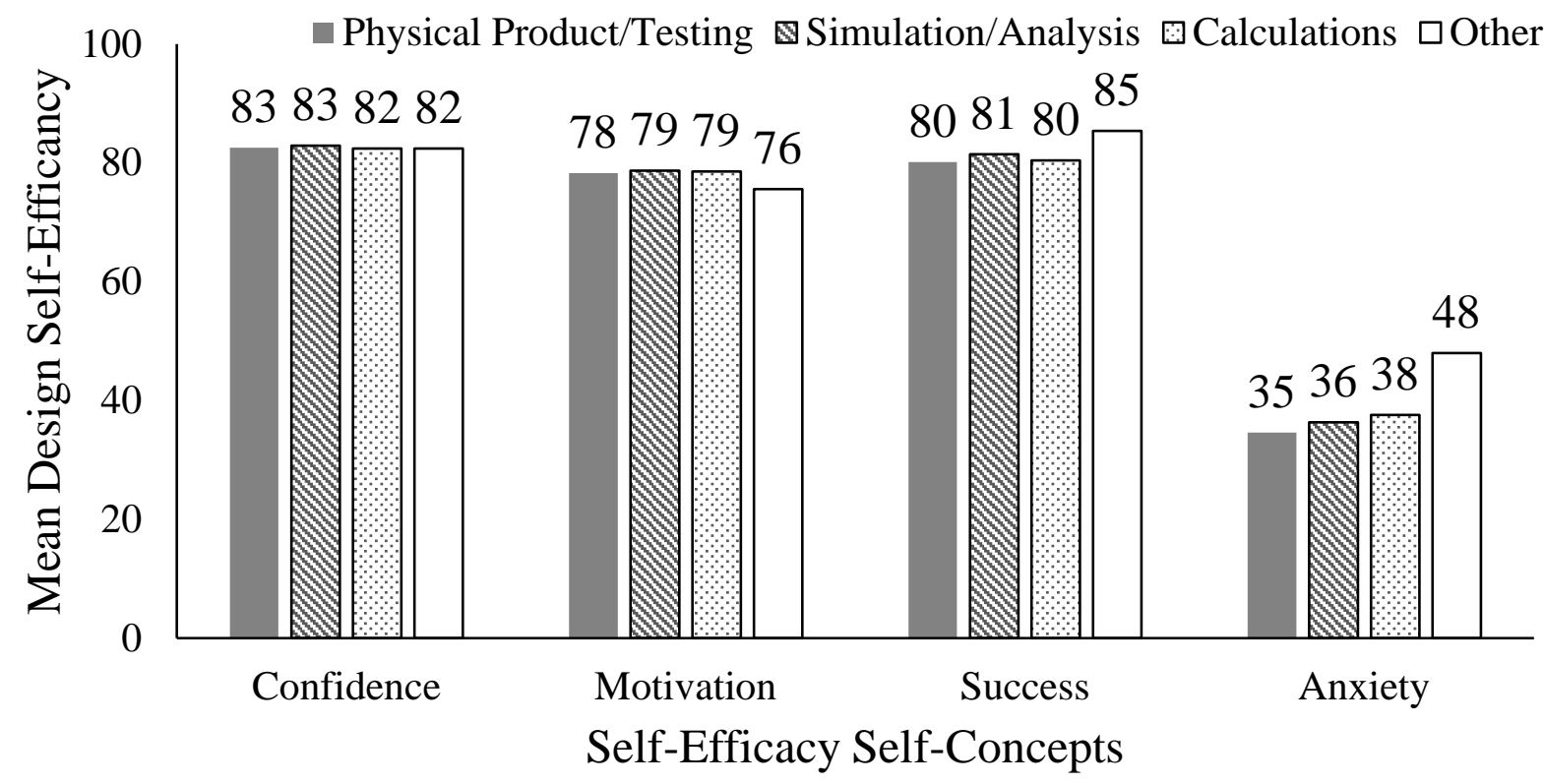

Figure 2. The mean engineering design self-efficacy, represented by the four design self-efficacy self-concepts, for the different project validation methods used by the students. Validation methods were physical product/testing (gray), simulation/analysis (diagonals), calculations (dotted), and other (white).

Table 4. One-way between subject ANOVA results for validation method used.

\begin{tabular}{|c|c|c|c|c|c|}
\cline { 2 - 6 } \multicolumn{1}{c|}{} & SS & df & MS & F-value & p-value \\
\hline Confidence & 26.123 & 3 & 8.708 & 0.079 & 0.971 \\
\hline Motivation & 158.931 & 3 & 52.977 & 0.229 & 0.877 \\
\hline Success & 614.934 & 3 & 204.978 & 1.567 & 0.196 \\
\hline Anxiety & 3566.444 & 3 & 1188.815 & 2.037 & 0.107 \\
\hline
\end{tabular}




\section{Design Self-Efficacy to Weekly Effort}

The mean values for the student responses regarding their self-efficacy and their average effort per week over the course of the entire project can be seen in Figure 3. In a small number of instances, students recorded multiple responses for average effort. The students' responses were therefore counted in each category. One-way ANOVAs showed that there were statistically significant effects of self-reported effort for all four self-concepts (Table 5). Post hoc comparisons were done using Tukey HSD tests, and the groups with statistically significant results are found in Table 6.

The students were asked to describe their perceived level of effort in terms of the average number of hours per week that they spent on the project, outside of lecture and studio time, over the two semesters. It is important to note that this survey did not measure the success of the final project, so the average number of hours per week cannot be said to correlate to improved project outcome. The results of the statistical analysis suggest that low effort levels (less than four hours per week) resulted in a lower confidence in approaching design tasks. This lower confidence may be tied to less experience with the design tasks as prolonged efforts have been proven to be a requirement for expert performance [23]. Another possible connection is that students with low motivation spend less time on their project: students who reported spending less than four hours a week reported a statistically lower motivation than those who reported spending more than four hours. Future work will investigate reasons behind feelings of low motivation. Expectations of success and anxiety levels were also shown to have tipping points at the four hour per week mark. Students who put in less than four hours reported a statistically significant lower expectation of success and higher anxiety than those putting in more than four hours. Anxiety levels did not show an improvement for all hours over four though; a lack of a statistically significant difference also existed for students spending more than 12 hours per week on their project. These students may be "high achieving students" who have personally set higher expectations for themselves, resulting in increased anxiety. Future work will further investigate perceived sources of anxiety to determine differences between the anxiety felt by the less than four hours/week students and those that reported over 12 hours/week.

Table 5. One-way between subject ANOVA results for weekly effort.

\begin{tabular}{|c|c|c|c|c|c|}
\cline { 2 - 6 } \multicolumn{1}{c|}{} & SS & df & MS & F-value & p-value \\
\hline Confidence & 922.479 & 3 & 307.493 & 2.889 & $\mathbf{0 . 0 3 5}$ \\
\hline Motivation & 4895.159 & 3 & 1631.720 & 7.015 & $<\boldsymbol{0 . 0 0 1}$ \\
\hline Success & 1745.842 & 3 & 581.947 & 4.229 & $\mathbf{0 . 0 0 6}$ \\
\hline Anxiety & 4778.066 & 3 & 1592.689 & 2.885 & $\mathbf{0 . 0 3 5}$ \\
\hline
\end{tabular}




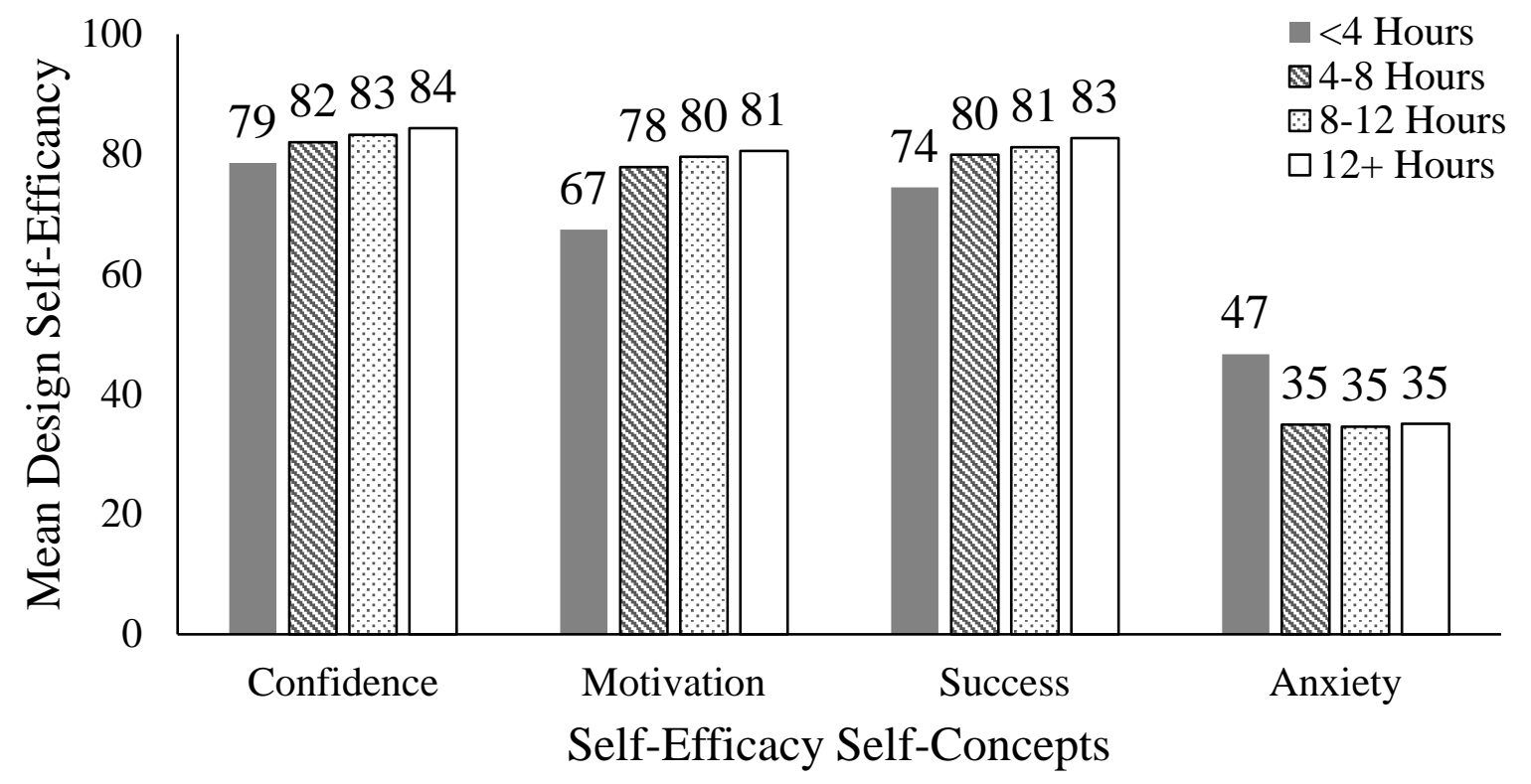

Figure 3. The mean engineering design self-efficacy, represented by the four design self-efficacy self-concepts, for the average amount of time students spent on their respective projects outside of lecture and studio hours. Responses were given as either less than 4 hours (gray), 4-8 hours (diagonals), 8-12 hours (dotted), or more than 12 hours per week (white).

Table 6. Summary of Tukey HSD results for weekly effort groups with statistically significant differences.

\begin{tabular}{|c|c|c|c|c|}
\hline Self-Concept & Group 1 & Group 2 & Q statistic & p-value \\
\hline Confidence & $<4$ hours & $12+$ hours & 3.833 & $\mathbf{0 . 0 3 5}$ \\
\hline Motivation & $<4$ hours & 4-8 hours & 5.479 & $\mathbf{0 . 0 0 1}$ \\
\hline Motivation & $<4$ hours & 8-12 hours & 6.072 & $\mathbf{0 . 0 0 1}$ \\
\hline Motivation & $<4$ hours & $12+$ hours & 5.892 & $\mathbf{0 . 0 0 1}$ \\
\hline Success & $<4$ hours & 4-8 hours & 3.705 & $\mathbf{0 . 0 4 5}$ \\
\hline Success & $<4$ hours & 8-12 hours & 4.325 & $\mathbf{0 . 0 1 3}$ \\
\hline Success & $<4$ hours & $12+$ hours & 4.787 & $\mathbf{0 . 0 0 4}$ \\
\hline Anxiety & $<4$ hours & 4-8 hours & 4.006 & $\mathbf{0 . 0 2 5}$ \\
\hline Anxiety & $<4$ hours & 8-12 hours & 3.907 & $\mathbf{0 . 0 3 0}$ \\
\hline
\end{tabular}

\section{Design Self-Efficacy to Project Satisfaction}

The mean values for the student responses regarding their self-efficacy and their satisfaction with their project can be seen in Figure 4. The one-way ANOVAs indicated that statistically significant differences exist for all four self-concepts (Table 7). The results for groups with significant differences can be found in Table 8.

Students with very high project satisfaction most likely had a positive experience, resulting in a higher design self-efficacy (higher confidence, higher motivation, higher expectation of success, 
and lower anxiety). They likely believe they can do well and will have a positive experience when faced with design tasks in the future. However, further study is required to understand what causes a student to be satisfied with their project because it does not necessarily correlate to successful project outcomes. Since project success is composed of a number of factors, future work will need to be conducted to define and assess project satisfaction as it relates to project outcomes.

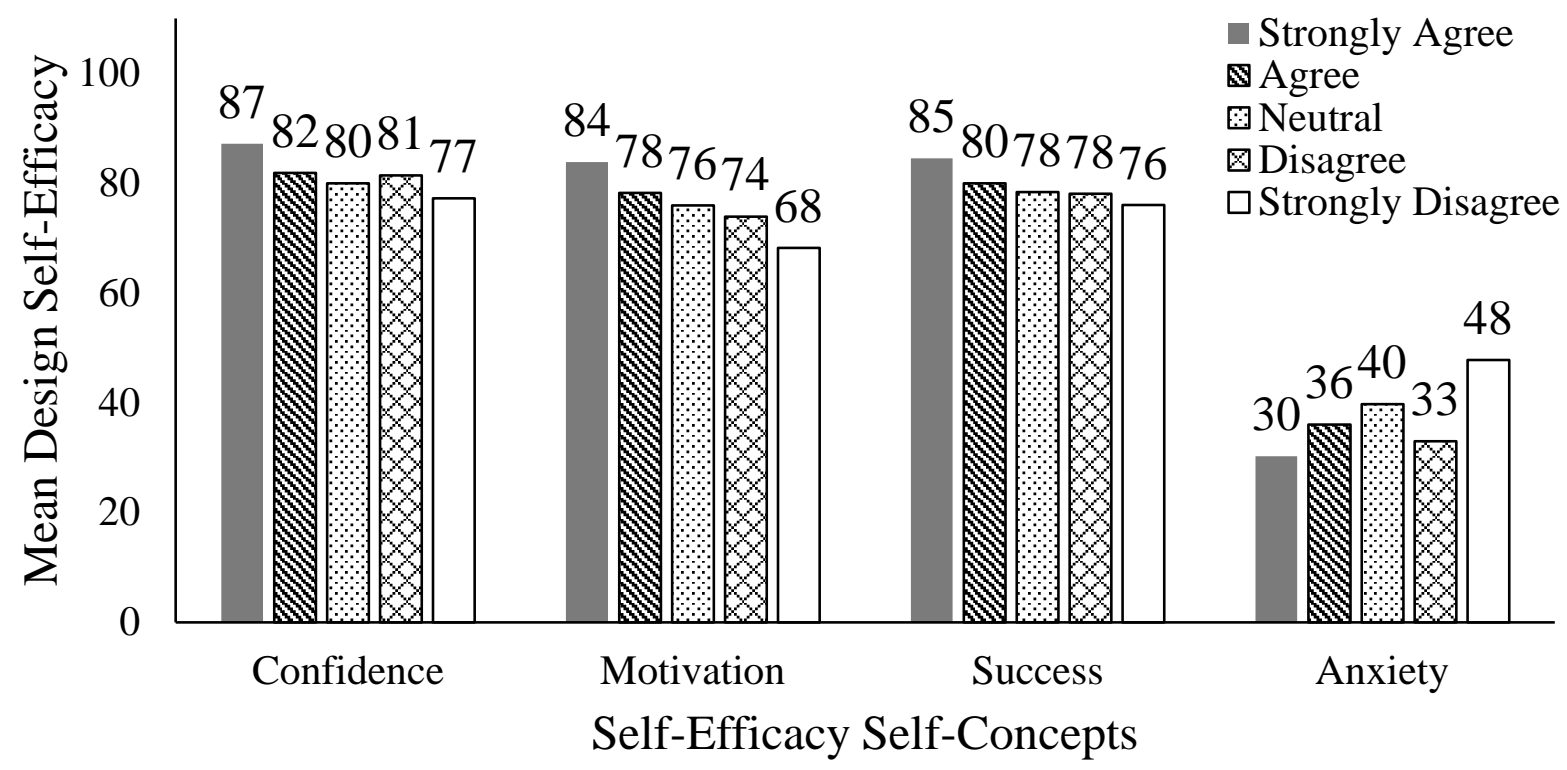

Figure 4. The mean engineering design self-efficacy, represented by the four design self-efficacy self-concepts show in the legend, for the level of project satisfaction. Responses were given as either strongly agree/satisfied (gray), agree/satisfied (diagonals), neutral (dotted), disagree/not satisfied (diamond), or strongly disagree/not satisfied (white).

Table 7. One-way between subject ANOVA results for project satisfaction.

\begin{tabular}{|c|c|c|c|c|c|}
\cline { 2 - 6 } \multicolumn{1}{c|}{} & SS & df & MS & F-value & p-value \\
\hline Confidence & 4189.434 & 4 & 1047.358 & 10.501 & $<\boldsymbol{0 . 0 0 1}$ \\
\hline Motivation & 8586.881 & 4 & 2146.720 & 9.528 & $<\boldsymbol{0 . 0 0 1}$ \\
\hline Success & 3346.022 & 4 & 836.505 & 6.195 & $<\mathbf{0 . 0 0 1}$ \\
\hline Anxiety & 10379.968 & 4 & 2594.992 & 4.822 & $<\mathbf{0 . 0 0 1}$ \\
\hline
\end{tabular}

Table 8. Summary of Tukey HSD results for project satisfaction groups with statistically significant differences.

\begin{tabular}{|c|c|c|c|c|}
\hline Self-Concept & Group 1 & Group 2 & Q statistic & p-value \\
\hline Confidence & Very satisfied & Satisfied & 6.332 & $\mathbf{0 . 0 0 1}$ \\
\hline Confidence & Very satisfied & Neutral & 7.189 & $\mathbf{0 . 0 0 1}$ \\
\hline Confidence & Very satisfied & Dissatisfied & 5.172 & $\mathbf{0 . 0 0 3}$ \\
\hline Confidence & Very satisfied & Very dissatisfied & 7.281 & $\mathbf{0 . 0 0 1}$ \\
\hline
\end{tabular}




\begin{tabular}{|c|c|c|c|c|} 
Motivation & Very satisfied & Satisfied & 4.393 & $\mathbf{0 . 0 1 7}$ \\
\hline Motivation & Very satisfied & Neutral & 5.206 & $\mathbf{0 . 0 0 2}$ \\
\hline Motivation & Very satisfied & Dissatisfied & 5.845 & $\mathbf{0 . 0 0 1}$ \\
\hline Motivation & Very satisfied & Very dissatisfied & 7.606 & $\mathbf{0 . 0 0 1}$ \\
\hline Motivation & Satisfied & Very dissatisfied & 5.115 & $\mathbf{0 . 0 0 3}$ \\
\hline Success & Very satisfied & Satisfied & 4.689 & $\mathbf{0 . 0 0 9}$ \\
\hline Success & Very satisfied & Neutral & 5.288 & $\mathbf{0 . 0 0 2}$ \\
\hline Success & Very satisfied & Dissatisfied & 4.917 & $\mathbf{0 . 0 0 5}$ \\
\hline Success & Very satisfied & Very dissatisfied & 5.375 & $\mathbf{0 . 0 0 2}$ \\
\hline Anxiety & Very satisfied & Neutral & 4.073 & $\mathbf{0 . 0 3 4}$ \\
\hline Anxiety & Very satisfied & Very dissatisfied & 5.528 & $\mathbf{0 . 0 0 1}$ \\
\hline Anxiety & Dissatisfied & Very dissatisfied & 4.231 & $\mathbf{0 . 0 2 4}$ \\
\hline
\end{tabular}

\section{Design Self-Efficacy to Sponsor Satisfaction}

The mean values for the student responses regarding their self-efficacy and their satisfaction with their sponsor can be seen in Figure 5. Statistically significant differences were identified for motivation and expectation of success (Table 9). Motivation and expectation of success for future design tasks showed some significant differences between those students who were very satisfied with their sponsor and those who were dissatisfied (Table 10). Additional study is needed to better understand how students score project sponsor satisfaction since the results were not consistent between groups.

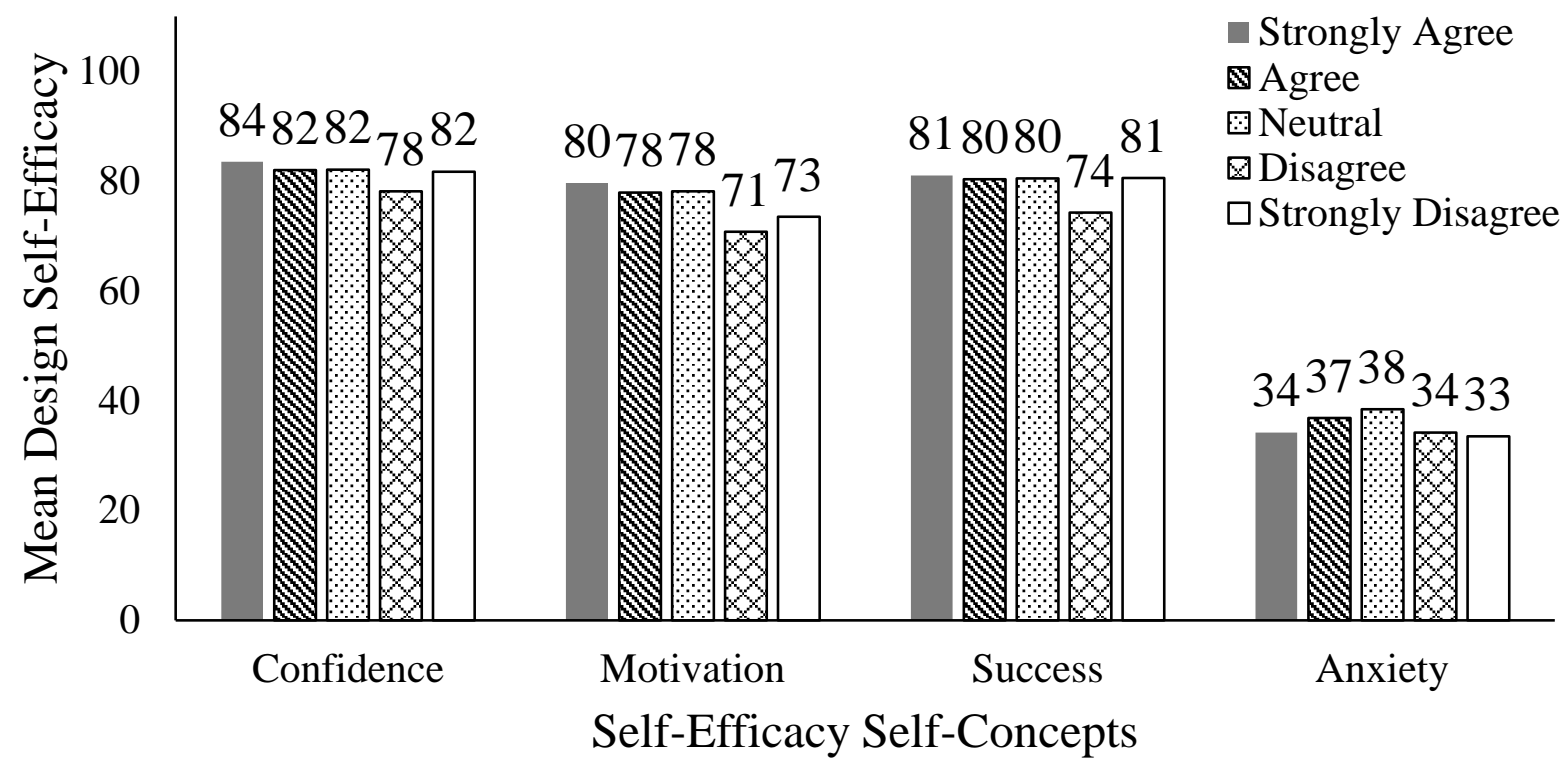

Figure 5. The mean engineering design self-efficacy, represented by the four design self-efficacy self-concepts show in the legend, for the level of project sponsor satisfaction. Responses were given as either strongly agree/satisfied (gray), agree/satisfied (diagonals), neutral (dotted), disagree/not satisfied (diamond), or strongly disagree/not satisfied (white). 
Table 9. One-way between subject ANOVA results for sponsor satisfaction

\begin{tabular}{|c|c|c|c|c|c|}
\cline { 2 - 6 } \multicolumn{1}{c|}{} & SS & df & MS & F-value & p-value \\
\hline Confidence & 898.196 & 4 & 224.549 & 2.104 & 0.079 \\
\hline Motivation & 2851.429 & 4 & 712.857 & 2.992 & $\mathbf{0 . 0 1 9}$ \\
\hline Success & 1365.403 & 4 & 341.351 & 2.462 & $\mathbf{0 . 0 4 5}$ \\
\hline Anxiety & 1462.345 & 4 & 365.586 & 0.662 & 0.619 \\
\hline
\end{tabular}

Table 10. Summary of Tukey HSD results for sponsor satisfaction groups with statistically significant differences.

\begin{tabular}{|c|c|c|c|c|}
\hline Self-Concept & Group 1 & Group 2 & Q statistic & p-value \\
\hline Motivation & Very satisfied & Dissatisfied & 4.375 & $\mathbf{0 . 0 1 8}$ \\
\hline Success & Very satisfied & Dissatisfied & 4.379 & $\mathbf{0 . 0 1 8}$ \\
\hline Success & Satisfied & Dissatisfied & 3.895 & $\mathbf{0 . 0 4 8}$ \\
\hline
\end{tabular}

\section{Design Self-Efficacy to Sponsor Guidance}

The mean values for the student responses regarding their self-efficacy and the level of guidance received from their sponsor technical customer can be seen in Figure 6. In a small number of instances, students' recorded ratings that did not match the values provided. The students' responses were therefore omitted from the analysis. No statistically significant difference was found for any of the four self-efficacy ratings (Table 11). This absence of a relationship may be due to the fact that most of the project guidance was derived from the course requirements themselves, which was consistent for all students. The academic requirements for the course are carefully structured to help guide the teams to apply design tools and complete the project. A coordinated group of studio instructors also helps to manage the teams and projects, keeping them aligned with the capstone format. Future work may attempt to relate project sponsor satisfaction with the level of guidance a sponsor provided to see if students show any preferences related to freedom in their design project.

Table 11. One-way between subject ANOVA results for sponsor guidance.

\begin{tabular}{|c|c|c|c|c|c|}
\cline { 2 - 6 } \multicolumn{1}{c|}{} & SS & df & MS & F-value & p-value \\
\hline Confidence & 210.438 & 4 & 52.609 & 0.484 & 0.748 \\
\hline Motivation & 2162.312 & 4 & 540.578 & 2.213 & 0.067 \\
\hline Success & 542.890 & 4 & 135.722 & 0.951 & 0.434 \\
\hline Anxiety & 1012.399 & 4 & 253.100 & 0.448 & 0.774 \\
\hline
\end{tabular}




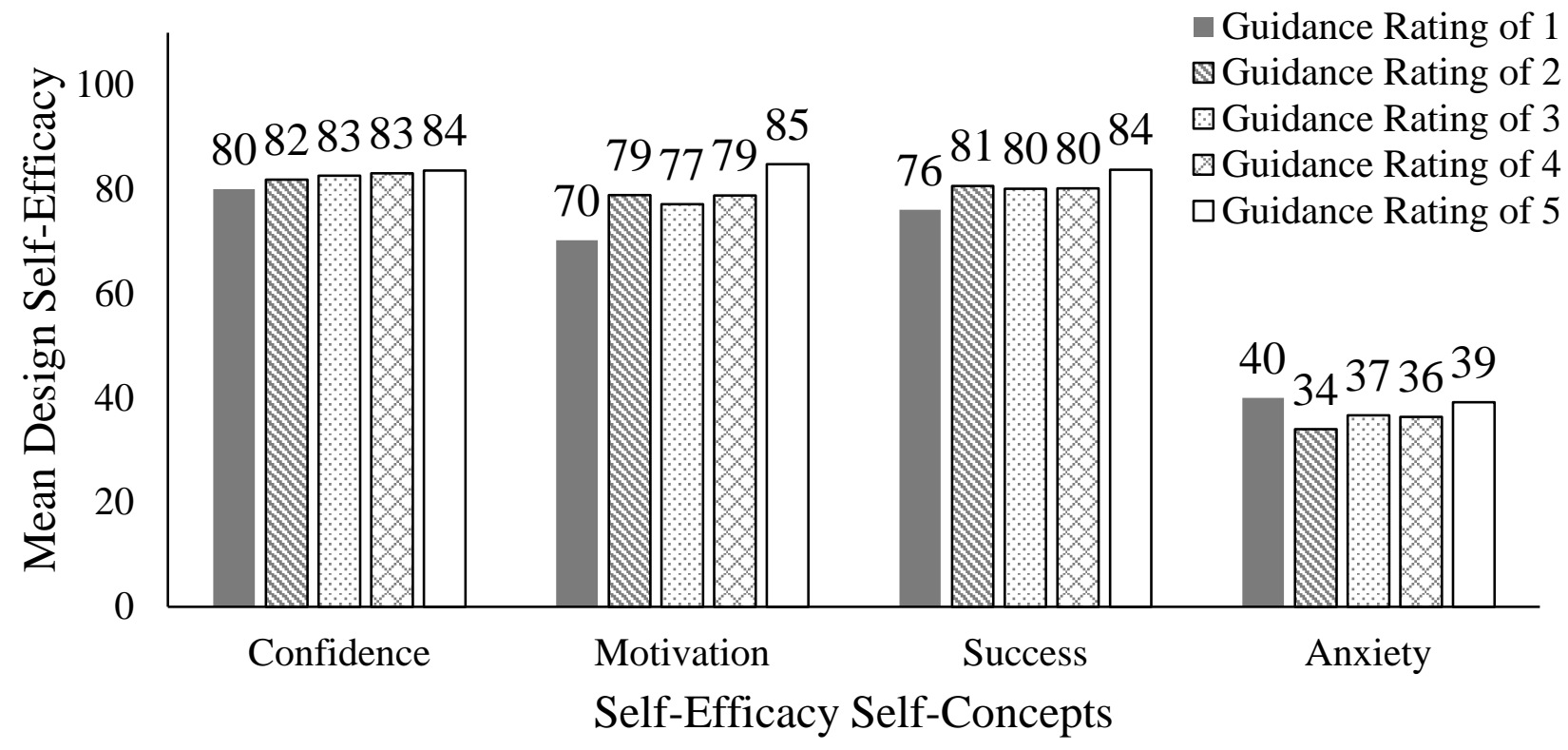

Figure 6. The mean engineering design self-efficacy, represented by the four design self-efficacy self-concepts, for the amount of guidance provided by the project sponsor. Responses were given as a range from 1-5, where 1 was no guidance (gray), 3 was collaborative (dotted), and 5 was told exactly what to do (white).

\section{Conclusions}

The study presented in this paper examined different factors in senior design projects to determine their impact on student design self-efficacy in terms of their confidence, motivation, expectation of success, and degree of anxiety to conduct future engineering design. Surprisingly, factors that can be adjusted by the senior design coordinator (type of sponsor, design validation method, amount of guidance provided by the sponsor) do not significantly affect student design self-efficacy. It is not necessary to encourage all teams to have the same senior design experience since all types of projects can result in high self-efficacy. Instead, design self-efficacy is strongly related to the level of effort put forth by the student and their satisfaction with their project. Students that spent an average of more than four hours per week on their project and those that had a high level of project satisfaction had significantly higher design self-efficacy. Design educators need to focus on student engagement and involvement in their senior design project to increase overall investment rather than the types of projects offered in the course. Future work will take the results one step further to investigate the variables positively affecting project satisfaction. Additional future work includes further study to identify commonalities in teams with high sponsor satisfaction since that factor had some influence on design self-efficacy. The results can be used to direct programmatic decisions and further improve the students' senior design learning outcomes and design self-efficacy.

\section{References}

[1] A. R. Carberry, H.-S. Lee, and M. W. Ohland, "Measuring Engineering Design SelfEfficacy," Journal of Engineering Education, vol. 99, no. 1, pp. 71-79, 2010/01/01 2010. 
[2] S. Y. Auyang, Engineering: An Endless Frontier. Cambridge, MA: Harvard University Press, 2004.

[3] J. Duderstadt, Engineering for a Changing World: A Roadmap to the Future of Engineering Practice, Research, and Education. Ann Arbor, MI: The Millennium Project, University of Michigan, 2008.

[4] Self-Efficacy in Changing Societies. Cambridge: Cambridge University Press, 1995.

[5] F. Pajares, "Self-Efficacy Beliefs in Academic Settings," Review of Educational Research, vol. 66, no. 4, pp. 543-578, 1996/12/01 1996.

[6] H. Kolar, A. Carberry, and A. Amresh, "Measuring computing self-efficacy," presented at the 120th ASEE Annual Conference \& Exposition, Atlanta, GA, June 23-26, 2013, 2013.

[7] J. Tsenn, D. A. McAdams, and J. S. Linsey, "A Comparison of Design Self-Efficacy of Mechanical Engineering Freshmen, Sophomores, and Seniors," presented at the 120th ASEE Annual Conference \& Exposition, Atlanta, Georgia, 2013/06/23, 2013. Available: https://peer.asee.org/19044

[8] R. Brennan and R. Hugo, "A Self-efficacy Survey for Engineering Graduate Attributes Assessment," presented at the 13th International CDIO Conference, Calgary, Canada, June 18-22, 2017, 2017.

[9] D. Seth, J. Tangorra, and A. Ibrahim, "Measuring undergraduate students' self-efficacy in engineering design in a project-based design course," presented at the 2015 IEEE Frontiers in Education Conference (FIE), El Paso, TX, USA, 21-24 Oct. 2015, 2015.

[10] "Criteria for Accrediting Engineering Programs: Effective for Reviews During the 20132014 Accreditation Cycle," Accreditation Board for Engineering and Technology, Baltimore2013.

[11] R. M. Marra, K. A. Rodgers, D. Shen, and B. Bogue, "Women Engineering Students and Self-Efficacy: A Multi-Year, Multi-Institution Study of Women Engineering Student Self-Efficacy," Journal of Engineering Education, vol. 98, no. 1, pp. 27-38, 2009/01/01 2009.

[12] E. J. Whitt, E. T. Pascarella, B. S. E. Nesheim, B. P. Marth, and C. T. Pierson, "Differences between women and men in objectively measured outcomes, and the factors that influence those outcomes, in the first three years of college," Journal of College Student Development, vol. 44, no. 5, pp. 587-610, 2003.

[13] R. M. Marra, C. Moore, S. M., and B. Bogue, "Women Engineering Students' SelfEfficacy Beliefs - The Longitudinal Picture," presented at the 2005 ASEE Annual Conference, Portland, Oregon, June 2005, 2005.

[14] H. Gaikwad and S. S. Kulkarni, "Self-Efficacy in Undergraduate Women in Engineering - A Case Study," Journal of Engineering Education Transformations, vol. 30, no. 1, 2016.

[15] N. Mamaril, "Measuring undergraduate students' engineering self-efficacy: a scale validation study," PhD, College of Education, University of Kentucky, Lexington, Kentucky, 2014.

[16] P. R. Pintrich and D. H. Schunk, Motivation in Education: Theory, Research, and Applications, 2nd ed. Upper Saddle River, NJ: Prentice Hall, 2002.

[17] A. J. Dutson, R. H. Todd, S. P. Magleby, and C. D. Sorensen, "A Review of Literature on Teaching Engineering Design Through Project-Oriented Capstone Courses," Journal of Engineering Education, vol. 86, no. 1, pp. 17-28, 1997/01/01 1997. 
[18] C. L. Dym, A. M. Agogino, O. Eris, D. D. Frey, and L. J. Leifer, "Engineering Design Thinking, Teaching, and Learning," Journal of Engineering Education, vol. 94, no. 1, pp. 103-120, 2005/01/01 2005.

[19] S. P. Schaffer, X. Chen, X. Zhu, and W. C. Oakes, "Self-Efficacy for Cross-Disciplinary Learning in Project-Based Teams," Journal of Engineering Education, vol. 101, no. 1, pp. 82-94, 2012/01/01 2012.

[20] J. C. Dunlap, "Problem-based learning and self-efficacy: How a capstone course prepares students for a profession," Educational Technology Research and Development, vol. 53, no. 1, pp. 65-83, 2005/03/01 2005.

[21] S. A. Ambrose, M. W. Bridges, M. DiPietro, M. C. Lovett, and M. C. Norman, How learning works: 7 research-based principles for smart teaching. San Francisco, CA: John Wiley \& Sons, 2010.

[22] E. Hilton, M. Tomko, A. Murphy, R. Nagal, and J. Linsey, "Impacts on Design SelfEfficacy for Students Choosing to Participate in a University Makerspace," presented at the The Fifth International Conference on Design Creativity (ICDC 2018), Bath, UK, 2018.

[23] K. A. Ericsson, R. T. Krampe, and C. Tesch-Römer, "The role of deliberate practice in the acquisition of expert performance.," Psychological review, vol. 100, no. 3, p. 363, 1993. 